\title{
QUANTITATIVE MEASUREMENT OF NASALITY IN EMR CHILDREN
}

\author{
DAVID A. DALY, EdD \\ The University of Michigan Speech Clinic, Ann Arbor, Michigan
}

\begin{abstract}
A new bioelectronic system for detecting and measuring voice parameters (TONAR) was used to quantify nasality in 50 educable mentally retarded children. Results indicated that over one-third of the children evaluated were hypernasal. The high prevalence of excessive nasality in EMR children was contrasted with (1) normative data on 78 nonretarded children collected with the bioelectronic system and (2) with prior incidence data based on listener judgments reported for retarded and nonretarded populations. The unique advantages of instrumental measurement of the elusive problem of hypernasality are discussed.
\end{abstract}

Of the four basic processes of speech production-respiration, phonation, resonation and articulation-disturbances in articulation are generally considered the most prevalent in mentally retarded populations. For example, the incidence figure of articulation disturbances reported in two separate studies of educable retarded youngsters (EMR) in special classes was 53\% (Steinman, Grossman, and Reece, 1963; Wilson, 1966).

Phonation and resonation disorders, however, are not uncommon in retarded populations and are believed to constitute the second major area of speech disturbance (Smith, 1968).

Schlanger and Gottleben (1957) noted that 240 of their 516 institutionalized subjects (46\%) had voice disorders. Blanchard (1964) also reported a substantial prevalence of voice problems among her 350 institutionalized children. She maintained that $31 \%$ of the residents had atypical voices. More recently, Marshall (1967) found that $32 \%$ of her 200 noninstitutionalized retarded children (IQ 40-70) demonstrated voice problems. The investigations attest to Matthews' (1971) statement that the incidence of voice disorders among retarded populations is high - considerably higher than in the general population.

Although many observations of the vocal quality of retarded persons have been subjective, definite descriptions have been made. Schlanger (1953), for example, diagnosed retarded subjects as having nasal, harsh and breathy voice qualities. Investigators seem to agree that hypernasality constitutes retarded persons' primary voice disturbance. Schlanger and Gottleben (1957) indicated that $26 \%$ of their voice-disordered group were hypernasal, whereas Marshall (1967) found that $35 \%$ of her subjects with voice problems demonstrated excessive nasality. Most of the literature germane to voice disturbances, however, has been dependent upon listener judgments, and human perceptions of voice qualities are 
known to vary widely. Perceptual evaluations are contaminated by fluctuating standard baselines against which personal judgments are made, and the attempts to share information among clinicians are hampered by the vagueness with which hypernasality is defined (Fletcher, 1970; Weatherly-White, Dersch and Anderson, 1964). Moreover, judgments of nasality have been shown to be in:uenced by speech characteristics such as pitch, loudness and how well the sounds are articulated (Sherman, 1954).

Instrumentation, which could provide valid and reliable measurement of nasality, has long been needed if clinicians are to state pretreatment conditions in universal terms. One such bioelectronic system has been developed and demonstrated with normal and cleft palate speakers (Fletcher, 1972).

The present investigation sought to further delineate the prevalence of hypernasality through bioelectronic instrumentation in one sample of retarded children; that is, the noninstitutionalized educable retarded.

\section{Description of Instrumentation}

Nasality was detected and measured with a recently developed bioelectronic instrumental system-TONAR. TONAR is an acronym that represents the words, The Oral Nasal Acoustic Ratio. The instrument separates and utilizes sound levels from both the oral and nasal channels to objectively detect, quantify and display nasalization in connected speech. The instrumental system consists of a sound separator unit, reinforcement panel and console unit. When a person speaks into TONAR's dual-microphoned sound separator, the instrument locks-on to the acoustic signal from the nasal cavity and simultaneously tracks the equivalent frequency band from the oral cavity. The system generates nasalto-oral acoustic ratios that compare the relative amounts of sound from the two chambers. A nasality meter on the console affords the clinician a continuous display of the client's acoustic ratios actually being generated as he speaks. Permanent printouts, called tonagrams, may be produced with an oscillographic recorder or X-Y plotter to display the amount and characteristics of nasality.

TONAR's nasality ratios have correlated significantly with perceptual judgments of nasality by groups of trained listeners (Fletcher and Bishop, 1970; Schulz, 1972). Thus, the instrument presents an efficient system to translate personal judgments into objective measurements.

TONAR is calibrated so that the complete range of normal through pathological nasality can be covered by a number system of $0 \%-100 \%$. Nasal-to-oral acoustic ratios varying between $0 \%$ and $15 \%$ are found in normal speakers when producing a standardized paragraph free from the nasal consonants $/ \mathrm{m} /$, $/ \mathrm{n} / \mathrm{and} / \mathrm{n} /$ (Fletcher, 1972). The opposite end of the scale is reached at ratios beyond $80 \%$ to $90 \%$ when substantial output is coming through the nose, and speech is unintelligible.

The reinforcement light panel becomes activated whenever a client produces 
lower nasality ratios than that specified on the console's goal ratio dial. This component of TONAR is used in modifying nasality and will not be elaborated here. Detailed descriptions of the unit and its clinical applications have been presented by the inventor (Fletcher, 1972; Fletcher and Sooudi, 1973).

\section{Subjects}

Fifty Caucasian EMR (IQ range from 56 to 80 with a mean of 66) children who attended special education classes in Birmingham, Alabama, served as the subjects. Chronological age (CA) levels ranged from 7-0 to 19-1 years with a mean age of 13-1 years.

\section{Procedure}

Each child was tested individually in the University of Alabama in Birmingham's Biocommunication Laboratory. Subjects were required to read or imitate a 75-word paragraph called the "Zoo Passage." This material was carefully designed to represent the distribution of all sounds in spoken English except the nasal consonants and has been reported elsewhere (Fletcher, 1972).

Each subject was seated in front of TONAR's sound separator and was instructed to place his upper lin snugly against the baffle plate so that his nose was in the upper chamber and his mouth was in the lower chamber. The adequacy of the sound separation obtained was tested by asking the client to say the sound "mmmm."

Ratios of $80 \%$ or higher indicated proper separation. Occasionally it was necessary to reposition a subject to insure adequate separation of the two sources of sound energy.

Responses were recorded on a TEAC Model A-6010 tape recorder for later analysis on TONAR. Visual displays of the acoustic ratios (tonagrams) were produced from an oscillographic recorder for easy analysis.

TONAR's nasal-to-oral acoustic ratios fluctuated so rapidly that both 1- and 10 -sec time averaging modes were used to simplify interpretation. Figure 1 shows both modes of analysis for an 8-year-old child, T. E. The 10-sec analysis is illustrated by the more stable line beginning at $5 \mathrm{sec}$ with an initial nasalty ratio of $30 \%$. The graph indicates a slight increase in nasality to a ratio of $37 \%$ by the end of the passage. T.E.'s speech productions were in the moderate nasality range with an overall ratio of $34 \%$. The more variable line represents the 1-sec time analysis. This boy had bursts in nasality up to 85\%. The dips in the graph to ratios of $2 \%$, however, were quite significant clinically, as they document his potential for modifiability. In this study the nasality ratios recorded during the standardized Zoo Passage were computed from the 10-sec time averaging mode. 


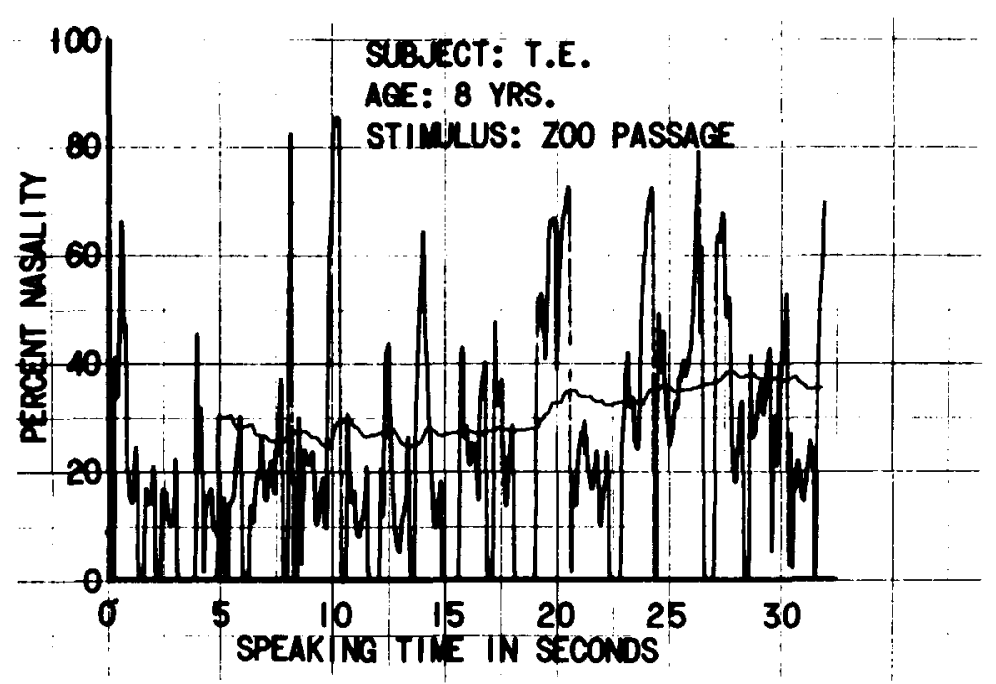

Fig. 1. Tonagram of an EMR subject illustrating both 10(stable nasality tracing) and $1-\sec$ (variable nasality tracing) time analyses.

\section{Results}

Table 1 shows the prevalence of nasality for the 50 EMR children according to severity classification. Their mean nasality ratio was $15 \%$ (the point between normal resonance and mild hypernasality) with the range varying from $0 \%$ to $70 \%$. The data revealed that $38 \%$ of the EMR children were hypernasal.

For comparative purposes the nasality ratios collected on 78 nonretarded chil dren drawn from kindergarten, second, fourth, sixth and eighth grade public school classes also are included in Table 1 . The mean nasality ratio for the normal group was $9.4 \%$ with a limited range of $0 \%-24 \%$. Only 3 of the 78 nonretarded children (4\%) showed excessive nasality, and all were in the mild classification.

\section{Discussion}

The prevalence data collected with TONAR on the 50 EMR children were slightly higher than incidence figures for retarded populations reported by previous investigators. TONAR analyses revealed that slightly over one-third (38\%) of the educable level children were hypernasal, whereas Schlanger and Gottleben (1957) and Marshall (1967) reported incidence figures of hypernasality in 
TABLE 1

Prevalence of Nasality in Normal ${ }^{a}$ and Educable Retarded Children

\begin{tabular}{|c|c|c|c|}
\hline Classification & & $\begin{array}{c}\text { Normal (\%) } \\
\qquad N=78\end{array}$ & $\begin{array}{c}\text { LMR }(\%) \\
N=50\end{array}$ \\
\hline Normal & $0-15$ & 96 & 62 \\
\hline Mild & $16-30$ & 4 & 18 \\
\hline Moderate & $31-45$ & 0 & 18 \\
\hline Severe & $46-60$ & 0 & 0 \\
\hline Very severe & $61-75$ & 0 & 2 \\
\hline Nasal consonants & $76-100$ & 0 & 0 \\
\hline \multirow[t]{3}{*}{ Total } & & 100 & 100 \\
\hline & Mean & 9.4 & 15.0 \\
\hline & Range & $0-24$ & $0-70$ \\
\hline
\end{tabular}

${ }^{a}$ Normative data after Fletcher (1973).

voice-disordered retarded children at $26 \%$ and $35 \%$, respectively. The prevalence figures in this study and Marshall's investigation are in relatively close agreement. TONAR's capability to detect near-normal levels of nasal resonance could account for the slightly higher figure.

The finding that more than one-third of the EMR children were hypernasal has a greater than passing interest for speech clinicians who must treat these children. Only 1 of the 50 children had a notable oral structure defect such as congenital cleft of the palate (this girl measured $70 \%$ nasal on TONAR). Lillywhite and Bradley (1969) have suggested a host of additional etiologic variables, such as capacious pharynx, submucous cleft, short palate or isolated paralysis of the soft palate, any of which certainly could influence hypernasality; we (Daly et al., 1971) have previously suggested that reduced oral diadochokinetic rates in EMR children may influence their proficiency in achieving adequate velo-pharyngeal closure.

Reported incidence figures for voice problems among samples of mentally retarded persons were considerably higher than the typical $1 \%$ incidence figure reported for the general population (Milisen, 1971). Many voice specialists, however, believe that the $1 \%$ incidence figure is questionably low. Wilson (1972) recently suggestcd $3 \%$ as a conservative cstimate of voice problems in children, whereas researchers such as Pont (1966), Baynes (1966) and James and Cooper (1966) maintain that their surveys of nonretarded children showed approximately 6\%-9\% having voice problems. Fletcher's (1973) recent study with TONAR and intellectually normal children yielded a $4 \%$ prevalence figure for hypernasality 
alone. Inclusion of other voice disturbances (e.g., hoarseness, harshness and breathiness) could feasibly bring the incidence figure closer to the $6 \%-9 \%$ range suggested by the above authors.

The findings of the present study give credence to Matthews' (1971) statement that

voice disorders are considerably more prevalent in retarded persons than in the general population. The children measured with TONAR in the present study, however, represent only one segment of mentally retarded persons; specifically, a sample of noninstitutionalized, educable, retarded children. Other EMR children in other schools, and perhaps in other regions of the country, should be quantitatively measured to verify the high prevalence figure reported here.

Nasality has traditionally been difficult to document perceptually because it is highly influenced by other speech characteristics such as pitch, loudness and general linguistic skill (Sherman, 1954). Furthermore, subjective comparisons by clinicians from different centers have confounded the task of consistently rating the presence or severity of a speaker's hypernasality (Weatherley-White, Dersch and Anderson, 1964).

Because TONAR is capable of monitoring speech continuously and accurately without being distracted by perceptually competing events, it affords the speech clinician unique advantages for dealing with the elusive problem of hypernasality. Objective assessment through bioelectronic instrumentation should lead the way to improved treatment procedures.

The work herein was partially supported by Project 910, U.S. Maternal and Child Health Service as awarded to the Center of Developmental and Learning Disorders, University of Alabama in Birmingham. The author is grateful to Hettie Johnson and Jean Covington for their assistance in the data collection, Tony Wilson for his technical assistance and to Sue Darnton for her critical review of the manuscript.

\section{References}

Baynes, R. A. An incident study of chronic hoarseness among children. JSpeech Hearing Dis., $1966,31,172-176$.

Blanchard, I. Speech patterns and etiology in mental retardation. Am. J. Mental Deficiency, 1964 , 68, 612-617.

Daly, D. A., Johnson, A. H. P., Smith, G., \& Fletcher, S. G. Diadochokinetic rate, length of lingual frenulum and speech articulation in normal and mentally retarded children. Paper presented at 47th Convention of Amer. Speech Hearing Association, Chicago, 1971.

Fletcher, S. G. Contingencies for bioelectronic modification of nasality. J. Speech Hearing Dis., 1972, 37, 329-346.

Fletcher, S. G. Normal levels of nasality for four types of spoken English utterances. Personal communication, 1973. 
Fletcher, S. G., \& Bishop, M. E. Measurement of nasality with TONAR. Cleft Palate, 1970, $7,610-621$.

Fletcher, S. G., \& Sooudi, I. A case report in joint prosthetics-speech treatment of hypernasality. J. Am. Dental Assoc, 1973, 87, 1418-1425.

James, H. P., \& Cooper, E. B. Accuracy of teacher referrals of speech handicapped children. Exceptional Child, 1966, 33, 29-33.

Lillywhite, II. S., \& Bradley, D. P. Communication problems in mental retardation: diagnosis and management. New York: Harper and Row, 1969.

Marshall, N. Oral deviations and speech and language disorders in 200 mentally retarded children. Unpublished manuscript. Portland, Ore.: University of Oregon Medical School, 1967.

Matthews, J. Speech problems of the mentally retarded. In L. E. Travis (Ed.), Handbook of speech pathology and audiology. New York: Appleton-Century-Crofts, 1971.

Milisen, R. The incidence of speech disorders. In L. E. Travis (Ed.), Handbook of speech pathology and audiology. New York: Applcton-Century-Crofts, 1971.

Pont, C. Hoarseness in children. W. Michigan Univ. J. Speech Therapy, 1965, 2, 6-8.

Schlanger, B. B. Speech measurements of institutionalized mentally retarded children. Am. J. Mental Deficiency, 1953, 58, 114-122.

Schlanger, B. B., \& Gottleben, R. H. Analysis of speech defects among the institutionally mentally retarded. J. Speech Hearing Dis., 1957, 22, 98-103.

Schultz, R. Is TONAR objective?: A pilot study. Unpublished manuscript. Long Beach, N. J.: Monmouth Medical Center, 1972.

Sherman, D. The merits of backward playing of connected speech in the scaling of voice quality disorders. J. Speech Hearing Dis., 1954, 19, 312-321.

Smith, R. M. Clinical teaching: methods of instruction for the retarded. New York: McGraw-Hill, 1968.

Steinman, J., Grossman, C., \& Reece, R. An analysis of the articulation of the educable mentally retarded child. Asha, 1963, 5, 791.

Weatherley-White, R. C., Dersch, W., \& Anderson, R. Objective measurcment of nasality in cleft palate patients: a preliminary report. Cleft Palate, 1964, 1, 120-124.

Wilson, D. K. Voice problems of children. Baltimore, Md.: Williams \& Wilkins, 1972.

Wilson, F. B. Efficacy of speech therapy with educable mentally retarded children. J. Speech Hearing Res., 1966, 9, 423-433. 